\title{
Evaluation of Water Resources Sustainable Utilization in Wuhan Based on the Model of SUDE
}

\author{
Lan $\mathrm{DONG}^{1}$ \\ Evergrande School of Management, Wuhan University of Science and Technology, \\ Wuhan 430080, China
}

\begin{abstract}
SUDE model is a systematic sustainable use model based on the view of the whole life cycle of water resources. The analysis of the model water resources has been divided into four stages according to the state of motion water resourcesat different times in its life cycle, namely the water supply stage ("S"), water use phase ("U"), water collection,treatment anddrainage stage("D") and water return to natural ecological (ecology) environment for dilution, degradation stage("E").on the analysis above,SUDE theoretical model of water system has been built and corresponding evaluation index systemhas therefore been established. Then, we use entropy weight TOPSIS method to evaluate thesustainability of water resource during 2013 2017 yearsin Wuhan, and finally the corresponding conclusions and suggestion have been drawn according to the result of evaluation in the paper.
\end{abstract}

Keywords: SUDE model, water resources, sustainability, entropy weight TOPSIS method

\section{Introduction}

Water system is not only the resource guarantee of a region's economic development, but also an important part of the natural ecological environment. The degree of its healthy and effective utilization is an important embodiment of the harmony between human society and nature, which directly affects the whole social and economic sustainability [1]. Therefore, it is an important element of sustainable development in a region.

The meaning of sustainable development is to meet the needs of the present generation and not to endanger the ability of future generations to meet their needs The sustainable use of water resources is defined as the whole process of supporting the coordinated development of population, resources, environment and economy and meeting the water needs of both within and between generations, while maintaining water sustainability and ecosystem integrity [2].

\section{Relevant Literature Review}

${ }^{1}$ Corresponding author: Lan Dong, Evergrande School of Management, Wuhan University of Science and Technology, Wuhan 430080, China; E-mail: strawberry_d@163.com. 
The research of sustainable water resources utilization in management concept and quantitative evaluation have been carried out. Koop (2015), Kasim (2014) believed that the sustainable use of water resources could be implemented through the establishment of a reasonable management framework $[3,4]$. From the perspective of global water use Wada et al. (2014) believed that the main ways could be explored and to improve the sustainability of water resourcesthrough the reconstruction of the past and the prediction of the future [5]. From the point of view of European water usage, water footprint methods were applied to evaluate the sustainability of water resources by Vanham (2017) [6]. From the perspective of promoting water management in watersheds, the assessment methods to promote regional sustainability by improving the sustainability of watershed water management has been studied (Cortes, 2012) [7]. Singh (2020), Fard (2020), from the perspective of urban water management in developing countries, discussed the of water resources sustainability through case studies of cities in India and Iran [8,9].

The sustainable management and evaluation methods of water resources has been also explored by domestic scholars from different levels. LiShuang (2019), LiYunjie (2016), GuoLidan (2020) and ZhangQian (2019) analyzed and evaluated the sustainable use of water resources in watersheds, provinces and cities using water ecological footprint method [10-13]. SunYaru (2019) and Liu Li (2020) used cloud models to analyze and evaluate the water safety of Nanjing city and the water sustainability level and spatial heterogeneity of nine cities in the PearlRiver delta respectively $[14,15]$. ZuoQiting (2020) used TOPSIS method to analyze the of water resources carrying capacity in nine provinces of the Yellow River Basin [16], and AiYadi (2020) used AHP-entropy weight method to evaluate the degree of water resources development in Xi'an [17]. For the northern part of China, water comes from underground, unlike surface water, groundwater has its own characteristics. For this type of region, scholars also used different analytical methods to study. Dong Yi (2019) selected the Bossel index system to evaluate the underground in Lishu County, Jilin Province [18]. Wang Lei (2019) used the AHP method to evaluate the groundwater safety in Yanbian Prefecture and put forward the countermeasures and for sustainable utilization [19].

For the evaluation of sustainable use of water resources, scholars at home and abroad mainly focus on scarcity, safety and carrying capacity, but from a systematic point of view, the sustainability of water resources has been studied by time axis, and the research is still in frame stage [20], especially the lack of practical evaluation.In this paper, water resources are regarded as a system, and the evaluation model of sustainable utilization of water resources has been established, and Wuhan has been taken as an example to make an empirical analysis.

\section{Overview of the Study Area}

Taking Wuhan as an example, this paper analyzes the sustainability of urban water system. Wuhan is the capital city of Hubei Province, known as the province of thousands of lakes, and the central city of central China.

Wuhan is located at the junction of the Yangtze River and the Han River and the eastern part of the Jianghan Plain. The landform belongs to the transition area of southeast Hubei hilly area from the eastern margin of the Han River Plain to the southern foot of Dabie Mountain. The north subtropical monsoon climate has the 
following characteristics, perennial abundant rainfall, abundant heat, cold winter and hot summer, distinct four seasons. There are many lakes in the city, accounting for about one quarter of the city's land area and a surface area of $2117.6 \mathrm{~km}^{2}$. There are 165 rivers within the urban length above $5 \mathrm{~km}$, the surface area of $471.31 \mathrm{~km}^{2} ; 166$ lakes listed in the protection list; the control area of the city is $867.07 \mathrm{~km} 2 ; 264$ reservoirs with a total storage capacity of 875 million $\mathrm{m}^{3}$.

With the increase of population, the acceleration of urbanization and the need of economic development, the water demand of cities increases greatly. At the same time, due to the instability of precipitation and the problems of surface water quality, there are still some problems in the supply, use and reuse of urban water system.

\section{Data sources and Research Methods}

\subsection{Data Sources}

The data in this paper are from China Statistical Yearbook [21], Hubei Statistical Yearbook [22], Wuhan Statistical Yearbook [23] and Wuhan Water Resources Bulletin [24].

\subsection{Research Methods}

\subsubsection{Determination of Evaluation Models}

SUDE model is a sustainable model based on the whole life cycle of water resources. The analysis of the model regards water medium as a natural resource, which is used by human society to meet the needs of normal residents, industrial production, fire protection and farmland irrigation, and the water after use is collected and treated by drainage pipe system according to the different degree of pollution. After reaching the drainage water quality index, this part of the water goes back to nature--into rivers, lakes and seas, or recharge groundwater. Therefore, water resources can be divided into four stages of life cycle, that is, resource supply stage ("S"), water use stage ("U"), water collection and treatment stage ("D") and water return to natural water ecological ("E") environment for dilution and degradation. SUDE model is established, as shown in figure 1 .

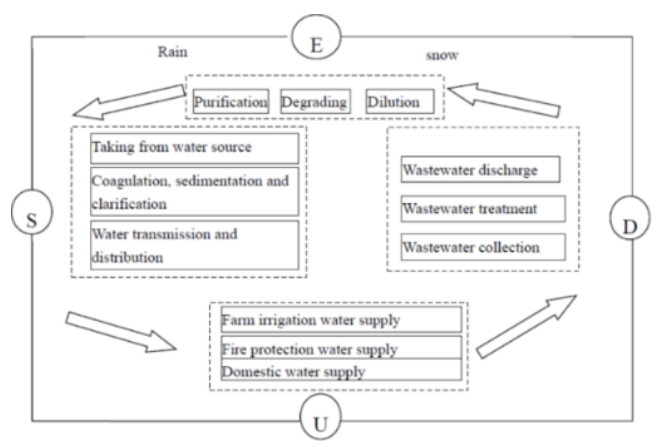

Figure1.The model of SUDE. 


\subsubsection{Determination of the Evaluation Method}

The entropy weight TOPSIS method is the synthesis of entropy weight and TOPSIS method. Firstly, the method uses the amount of information carried by the evaluation index data, that is, the entropy weight method is used to give the index weight, and then the evaluation object is calculated and sorted by the TOPSIS method. On this basis, the optimal evaluation object is obtained. This evaluation method belongs to the objective evaluation method, which can make full use of the information of the data and effectively eliminate the influence between different indexes by the same trend and normalization of the original data.

The paper firstly assimilates and normalizes the original data to eliminate the influence between different indexes, then calculates the weight of each evaluation index in the SUDE model by entropy weight method, and then uses the TOPSIS to calculate the ranking of the evaluation objects.

\section{Establishment of the Evaluation System and the Index Calculation}

\subsection{Establishment of the Evaluation System}

Based on the above analysis, we can establish the evaluation indicators of SUDE, as shown in Table 1.

Table 1. Water system sustainability evaluation index system based on SUDE.

\begin{tabular}{|c|c|c|c|c|c|}
\hline \multirow{2}{*}{\multicolumn{4}{|c|}{$\begin{array}{l}\text { three-level indicators } \\
\text { the first the Second }\end{array}$}} & \multicolumn{2}{|c|}{ weight of indicators } \\
\hline & & & & the Second & the third \\
\hline & S2 & Total volume of water supply $\left(10^{8} \mathrm{~m}^{3}\right)$ & - & & 0.0430 \\
\hline $\mathbf{S}$ & S4 & $\begin{array}{l}\text { The percentage of water quality standards in the first-level water } \\
\text { functional area (\%) }\end{array}$ & + & 0.2434 & 0.0383 \\
\hline & S5 & Length of the water supply pipe network $(\mathrm{km})$ & + & & 0.0419 \\
\hline & U1 & Water consumption volume of ten thousandyuan GDP $\left(10^{8} \mathrm{~m}^{3}\right)$ & - & & 0.0307 \\
\hline $\mathbf{U}$ & U4 & $\begin{array}{l}\text { Domestic water consumption volume of urban residents per person per } \\
\text { day }(l)\end{array}$ & - & & 0.0396 \\
\hline & U5 & The percentage of water supply population in central areas $(\%)$ & + & & 0.0341 \\
\hline & D1 & The average volume sewage discharge per person per year $\left(10^{4} \mathrm{~m}^{3}\right)$ & - & & 0.0281 \\
\hline & D2 & Total volumesewage discharge of industrial wastewater $\left(10^{4} \mathrm{~m}^{3}\right)$ & - & & 0.0330 \\
\hline D & D6 & Total volume of COD discharge of urban domestic sewage $\left(\mathrm{m}^{3}\right)$ & - & 0.4144 & 0.0334 \\
\hline $\begin{array}{l}\mathrm{S} \\
\mathrm{U}\end{array}$ & D7 & $\begin{array}{l}\text { Total volume of Ammonia nitrogen discharge in the urban domestic } \\
\text { sewage }\left(\mathrm{m}^{3}\right)\end{array}$ & - & & 0.0312 \\
\hline $\mathrm{D}$ & D8 & The percentage of industrial water reuse $(\%)$ & + & & 0.0617 \\
\hline $\mathrm{E}$ & D9 & Thepercentage of centralized treatment of urban domestic sewage (\%) & + & & 0.0277 \\
\hline & D10 & Length of the drainage pipe $(\mathrm{km})$ & + & & 0.0312 \\
\hline & E1 & $\begin{array}{l}\text { Investment in ecological construction and protection completed within } \\
\text { the year }\left(10^{4} \text { yuan }\right)\end{array}$ & + & & 0.0266 \\
\hline & E2 & The average area of park green space occupied by per person $\left(10^{4} \mathrm{ha}\right)$ & + & & 0.0330 \\
\hline $\mathbf{E}$ & $\mathbf{E 3}$ & Greening coverage rate in built-up areas & + & 0.1454 & 0.0227 \\
\hline & $\mathbf{E 4}$ & Length of the levee & + & & 0.0413 \\
\hline & $\mathbf{E 5}$ & Direct economic loss value of geological disasters & - & & 0.0218 \\
\hline
\end{tabular}




\subsection{TheIndex Calculation}

The steps for the calculation are as follows.

(1) Establish a matrix composed of the original index data

Establish an original index data matrix that indicates the number of samples as "m", evaluation index is " $n "$, as follows:

$$
\mathrm{X}=\left[\begin{array}{ccc}
\mathrm{x}_{11} & \cdots & \mathrm{x}_{1 \mathrm{n}} \\
\vdots & \ddots & \vdots \\
\mathrm{x}_{\mathrm{m} 1} & \cdots & \mathrm{x}_{\mathrm{mn}}
\end{array}\right]
$$

(2) Assimilation and normalization processing of data

1)The positive and negative Indicators are assimilated to obtain the matrix $X_{i j}^{\prime}$

The positive Indicators: $\mathrm{X}_{\mathrm{ij}}^{\prime}=\frac{\left(\mathrm{x}_{\mathrm{j}}-\mathrm{X}_{\mathrm{min}}\right)}{\left(\mathrm{X}_{\max }-\mathrm{X}_{\min }\right)}$

The negative Indicators: $\mathrm{X}_{\mathrm{ij}}^{\prime}=\frac{\left(\mathrm{x}_{\max }-\mathrm{X}_{\mathrm{j}}\right)}{\left(\mathrm{X}_{\max }-\mathrm{X}_{\min }\right)}$

In the formula above, $X_{\max }$ is the maximum of the $\mathrm{j}$ indicator and $\mathrm{X}_{\min }$ is the minimum of the $\mathrm{j}$ indicator.

2)The data matrix is normalized to obtain a standardized matrix consisting of processed data, namely

$$
\begin{gathered}
\mathrm{Z}_{\mathrm{ij}}=\frac{\mathrm{x}_{\mathrm{ij}}^{\prime}}{\sqrt{\sum\left(\mathrm{x}_{\mathrm{ij}}^{\prime}\right)^{2}}} \\
\mathrm{Z}=\left[\begin{array}{ccc}
\mathrm{Z}_{11} & \cdots & \mathrm{z}_{1 \mathrm{n}} \\
\vdots & \ddots & \vdots \\
\mathrm{z}_{\mathrm{m} 1} & \cdots & \mathrm{z}_{\mathrm{mn}}
\end{array}\right]
\end{gathered}
$$

(3) Determination of the weights of the index data in the matrix

The weight of the index data is determined using the entropy weight method.

1) After the normalization of the matrix $X_{i j}^{\prime}$, a dimensionless treatment is performed to obtain the matrix $\mathrm{P}_{\mathrm{ij}}$

$$
P_{i j}=\frac{x_{i j}^{\prime}}{\sum_{i=1}^{m} x_{i j}^{\prime}}
$$

2)

$$
\begin{aligned}
e_{j}=\frac{-1}{\ln m} \sum_{i=1}^{m} P_{i j} \times \ln P_{i j} & \\
d_{j} & =1-e_{j} \\
W_{j} & =\frac{d_{j}}{\sum_{j=1}^{n} d_{j}}
\end{aligned}
$$


3) $\mathrm{Z}_{\mathrm{ij}}{ }^{*}=\mathrm{W}_{\mathrm{j}} \times \mathrm{Z}_{\mathrm{ij}}$

(4) Calculating the optimal solutionZ ${ }_{\mathrm{J}}^{*+}$ And the worst solution $\mathrm{Z}_{\mathrm{J}}{ }^{*-}$

(5) Calculating the distance between the evaluation object and the optimal solution $\mathrm{D}_{\mathrm{i}}{ }^{+}$; calculating the distance between the evaluation object and the worst solution $\mathrm{D}_{\mathrm{i}}^{-}$, and then determining the comprehensive index $\mathrm{Ci}$

$$
\begin{gathered}
\mathrm{D}_{\mathrm{i}}^{+}=\sqrt{\sum_{\mathrm{j}=1}^{\mathrm{n}}\left(\mathrm{Z}_{\mathrm{ij}}^{*+}-\mathrm{Zij}\right)^{2}} \\
\mathrm{D}_{\mathrm{i}}^{-}=\sqrt{\sum_{\mathrm{j}=1}^{\mathrm{n}}\left(\mathrm{Z}_{\mathrm{ij}}^{*-}-\mathrm{Zij}\right)^{2}} \\
\mathrm{C}_{\mathrm{i}=\frac{\mathrm{D}_{\overline{\mathrm{i}}}}{\mathrm{D}_{\mathrm{i}}^{+}+\mathrm{D}_{\mathrm{i}}^{-}}}
\end{gathered}
$$

Computing the value of $\mathrm{C}_{\mathrm{i}}$, the comprehensive index of each evaluation object. And judge the order of the scheme according to the size of its value. Then, combined with the evaluation level standard (As shown in Table 2), the evaluation object, namely, the level of the sustainable utilization of the water resources can be obtained. We also could find the change of water utilization of Wuhan water resources (as shown

\begin{tabular}{|c|c|c|c|c|c|}
\hline closeness & $\begin{array}{l}{[0,0.2]} \\
\text { Weak }\end{array}$ & $\begin{array}{c}\quad(0.2,0.4] \\
\text { Relatively weak }\end{array}$ & $\begin{array}{c}(0.4,0.6] \\
\text { Medium level }\end{array}$ & $\begin{array}{c}\quad(0.6,0.8] \\
\text { Relativelystrong }\end{array}$ & $\begin{array}{c}(0.8,1.0] \\
\text { strong }\end{array}$ \\
\hline & V & IV & III & II & I \\
\hline
\end{tabular}
in figure 2).

Table 2. The evaluation level standard of the sustainable utilization of the water resources.

\section{Analysis of the Evaluation Results of the Sustainable Utilization of Water Resources}

According to the sample data of 2013 2017, the sustainable utilization level of Wuhan water system is calculated. Thecalculation results including the weight of indicatorsand the level of the sustainable utilization are shown in Table 1and 3 respectively. According to the calculation results, the sustainable utilization level of the water system in Wuhan is showing a good development trend, and the sustainable utilization capacity is gradually improved. Among them, the water system sustainable utilization comprehensive indexesof 2013 and 2014 were 0.3194 and 0.3455 , respectively, which were at the lower level. While the subsequent index of 2015 year reached 0.4319 , rising to the medium level. The indexes of 2016 and 2017 were divided into 0.6657 and 0.6147 , respectively, showing that the sustainable utilization of water resources in Wuhan has entered a good level of development. 
Table 3. The level of the sustainable utilization of Wuhan water resources (2013 2017).

\begin{tabular}{llllc}
\hline & $\mathrm{d}_{\mathrm{i}}^{+}$ & $\mathrm{d}_{\mathrm{i}}^{-}$ & $\mathrm{c}_{\mathrm{i}}$ & level \\
\hline 2013 & 0.1583 & 0.0574 & 0.2660 & IV \\
2014 & 0.1515 & 0.0482 & 0.2414 & IV \\
2015 & 0.1273 & 0.0618 & 0.3332 & III \\
2016 & 0.0613 & 0.1492 & 0.7088 & II \\
2017 & 0.1083 & 0.1220 & 0.5296 & III
\end{tabular}

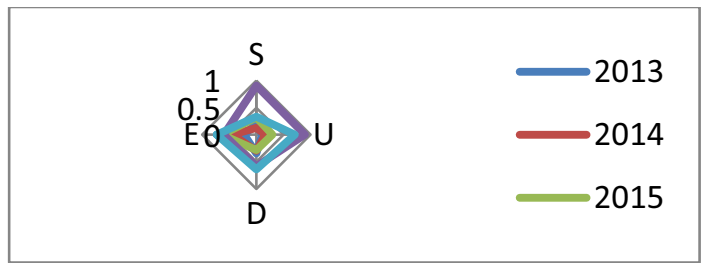

Figure2. the Change of water utilization of Wuhan water resources (2013 2017).

(1) Analysis the four subsystems of the SUDE (As shown in Table 4), the development index of the subsystem S ranged from the lower level of 2013 2015 years, continuously increasing thereafter, especially in 2016 year, reaching the peak. The main reasons of the index increasing depends on the increasing of the total volume of water resources and the transit water volume. That year had $29.4 \%$ more rainfall than in the past year and the volume of rainfall in that year was $46.2 \%$ more than the multi-year average. In 2017 year, the volume of rainfall year was $6.7 \%$ less than the annual average, and water supply levels declined at the sametime.

Table 4. Sustainable utilization index value of SUDE system and its subsystem of Wuhan (2013 2017).

\begin{tabular}{lcccc}
\hline & $\mathrm{S}$ & $\mathrm{U}$ & $\mathrm{D}$ & $\mathrm{E}$ \\
\hline 2013 & 0.2088 & 0.1072 & 0.3445 & 0.2229 \\
2014 & 0.1269 & 0.1660 & 0.2958 & 0.4438 \\
2015 & 0.3199 & 0.2967 & 0.2827 & 0.6340 \\
2016 & 0.9077 & 0.8975 & 0.5815 & 0.5999 \\
2017 & 0.3344 & 0.7109 & 0.6393 & 0.7307 \\
\hline
\end{tabular}

(2) The value of development index of the subsystem U of SUDE was in the $[0,0.2]$ interval with a low level of sustainable development in 2013 year, and was in the interval of $(0.2,0.4]$ with a relatively low level of in 2014 and 2015 year. After 2016, it showed a highlevel of development trend. Relatively speaking, the level of urbanization in 2013 2015 was not very high, so the demand for domestic water consumption volume of urban residents per person per day was relatively low. But at the same time, due to the lack of science and technology level and the lack of water-saving consciousness, the number of agricultural mu average irrigation water and industrial 10,000 yuan added value water in this period remained high. But at the same time, due to the low level of science and technology and the lack of water-saving consciousness, both Water consumption volume of farmland irrigation per mu area and Water consumption volume of the industrial added value of ten thousand yuanin this period remained high.

Especially after 2016, the proportion of water supply population in the central urban area increased, both the sanitary conditions of the whole society and the water supply efficiency of the water system were improved, which ensured that the relative levels of the subsystem $U$ in both 2016 and 2017 year were higher.

(3) In the subsequent system D, the discharge volume of industrial wastewater and urban domestic sewage, COD and ammonia nitrogen emissions, although repeated but 
showed an overall downward trend, indicating the improvement of drainage water quality, which is quite friendly to the environmental system. However,as the important indexes, which were reflected in the industrial and domestic sewage treatment capacity_ the percentage of industrial water reuse and the percentage of centralized treatment of urban domestic sewage,were continuously improved, which depends on the increase of Wuhan municipal government investment in the environmental foundation such as drainage pipe network and the enhancement of the supervision of the sewage treatment level of industrial enterprises and sewage treatment plants.

(4) Similar to the system D, the sustainable level of subsystem E increased year by year after experiencing lower levels in 2013. The investment of ecological construction and protection by Wuhan Municipal Government ensured the improvement and development of ecological aspects such as the average area of park green space occupied by per person, greening coverage rate in built-up areas and the length of the levee. And at the same time, the sustainability of the whole ecological subsystem E has been also ensured.

The sustainable development trend of SUDE analyzed abovehasbe shown in figure 3 .

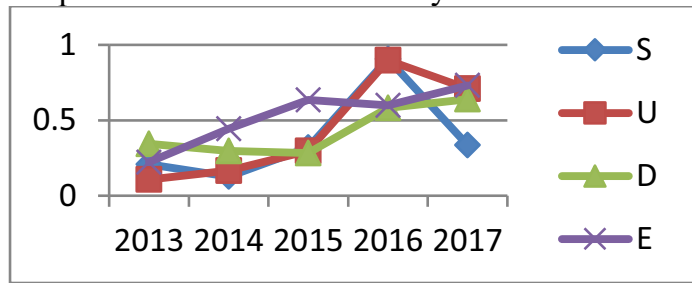

Figure 3. Sustainable development trend of SUDE subsystem in Wuhan (2013 2017).

\section{Conclusion and Suggestions}

(1) Compared with the previous evaluation index system, the urban water system based on SUDE model can analyze the problems from the system perspective, help to identify and select some important relevant factors which belong not only to the aspects of technology but also to the aspects of technology management, and better reflect the internal connection between the elements of the urban water system. In addition, the selection of indicators also considers the operability and reliability of data collection.

(2) Efforts should be strengthened continuously to ensure the supply quality of water resources. In particular, we should not rely on the endowment of water resources, efforts should be made to improve the compliance rate of the first-level water functional zones and strengthen the construction of the water supply pipe network.

(3) Improve the efficiency of water use, increase the promotion of agricultural irrigation technology, and continuously strengthen water saving publicity among urban residents, improve the awareness of water saving, while ensuring that the quality of living standards not decline. The total amount of water would be appropriately reduced,so as to reduce the pressure of urban water supply.

(4) Continue to strengthen supervision, especially for the supervision of drainage points near surface water, strengthen enterprise regular inspection and sampling inspection, so as to ensure the normal operation of sewage treatment facilities, which can not only improve the circulation rate of water treatment to reduce the volume of sewage water, but also reduce the water quality of sewage water, to achieve the dual control goal of quality and quantity. 
(5) Increase investment in ecological construction. While nature gives us water resources through rainfall, it also threatens us with possible disasters such as floods. Withpreventing disasters in the bud, increasing ecological protective efforts, increasing the protection and construction of green space and wetlands, improving the runoffcoefficient of drainage to improve the natural water storage capacity, we could relieve the transportation and discharge pressure of the artificial drainage system, so as to ensure that the city passes safely during the onceinacentury flood disaster.

\section{References}

[1] Niu W. Introduction to sustainable development. Sci. Press; 1994.1-123 p.

[2] Feng S. Introduction to the continuous utilization and management of water resources. Sci. Press; 2000.62-214 p.

[3] Koop S, Leeuwen CJ. Assessment of the sustainability of water resources management: a critical review of the city blueprint approach.Water Resources. 2015 Sept; 29(15) :5649-70.

[4] Kasim A,Gursoy D, Okumus F, Wong A. The importance of water management in hotels: a framework for sustainability through innovation.J. of Sustainable Tourism.2014 Jul;22(7) :1090-107.

[5] Wada Y, Bierkens MF. Sustainability of global water use: past reconstruction and future projections.Environ. Res. Lett. 2014 Oct; 9 (10):1-17.

[6] Vanham D. The water footprint of the EU: quantification, sustainability and relevance.Water Int. 2018.Jun; 43(6):731-45.

[7] Cortés AE, Oyarzún R, Kretschmer N, Chaves H, Soto G, Soto M, Amezaga J, Oyarzun J, Rotting T, Senoret M. Application of the watershed sustainability index to the elqui river basin north-central chile. Obras Y Proyectos. 2012.12:57-69.

[8] Singh AP, Bhakar P. Development of groundwater sustainability index: a case study of western arid region of Rajasthan, India.Environment Development and Sustainability. 2020.2.

[9] Fard ZD, Rahimi M , Javid N. Studying radon concentration in drinking water resources in Zarand city (Iran) and its villages, J.R.N..2020 Aug; 326 (8):33-9.

[10] Li S, Du JK, Xing HH, Wang SX, Li F. Sustainable utilization evaluation of water resources in the main stream of Hangjiang river based on water footprint theory and grey target model.Water Saving Irrigation. $2019 \mathrm{Sept} ;$ (9):74-80.

[11] $\mathrm{Li} \mathrm{YJ,} \mathrm{Lu} \mathrm{HJ} \mathrm{,} \mathrm{Bu} \mathrm{P.} \mathrm{Sustainable} \mathrm{utilization} \mathrm{of} \mathrm{water} \mathrm{resources} \mathrm{in} \mathrm{Zhejiang} \mathrm{province} \mathrm{based} \mathrm{on}$ ecological footprint analysis. J. of Yangtze River Scientific Research Institute. 2016 Dec;33(12):22-6,32.

[12] Guo LD , Jing PR. Evaluation of sustainable utilization of water resources in Jiangsu province based on ecological footprint theory.J. of Economics of Water Resources. 2020 Mar; 38(3):19-26.

[13] Zhang Q, Xie SY. Using Ecologicalwater footprint model to analyze sustainable use ofwater resources in Chongqing.J. of Irrigation and Drainage. 2019 Mar; 38(3):93-100.

[14] Sun YR, Dong ZC, Xv Y, Bao QY. Urban water security evaluation based on cloud model.Yellow River. 2019 Aug; 41(8):52-6.

[15] Liu L ,Wang L. The entropy weights-based approach to and the normal cloud model for water resources assessment.J. ofSouth China Normal University(Natural Science Edition). 2020 Jan;52(1): 77-84.

[16] Zuo QT, Zhang ZZ, Wu BB. Evaluation of water resources carrying capacity of nine provinces in Yellow River basin based on combined weight topsis model.Water Resources Protection. 2019 Feb;36(2):1-7.

[17] Ai YD, Wei CJ , Ma ZZ. Evaluation on water resources development and utilization degree based on ahp-entropy weight method.Advances in Science and Technology of Water Resources. 2020 Feb;:40(2):11-6.

[18] Dong Y, Liang XJ, Xiao CL, Wang YF. Sustainable utilization assessment of groundwater resources in Lishu county based on bossel index system. Water Power. 2019 Jan;45(1): 9-12.

[19] Wang L, Liang XJ, Li HW ,Lu H. Study on sustainable utilization of groundwater resources in Yanbian prefecture based on water safety.Yangtze River. 2019 May;50(5):94-8.

[20] Gao CB, Zeng HY, Chen XG ,Chen JW. Evaluation of environmental sustainability for urban water systems based on lca framework. Water Resources Protection. 2007 Feb;23(2):51-3.

[21] National Bureau of Statistics of China. China statistical yearbook 2013-2018. China Statistics 
Press;2019.

[22] National Bureau of Statistics of China. Hubei statistical yearbook 2013-2018. Beijing: China Statistics Press; 2019.

[23] Wuhan Minicipal Statistics Bureau. Wuhan statistical yearbook 2013-2018. Beijing: China Statistics Press; 2019. [24] Wuhan Municipal Water
Bulletinhttp://swj.wuhan.gov.cn/szy

Resources Bureau.Wuhan Water Resources 